\title{
Instruments to Measure Disease Activity in Systemic Lupus Erythematosus - Is Our Net Tight Enough to Catch the Hydra?
}
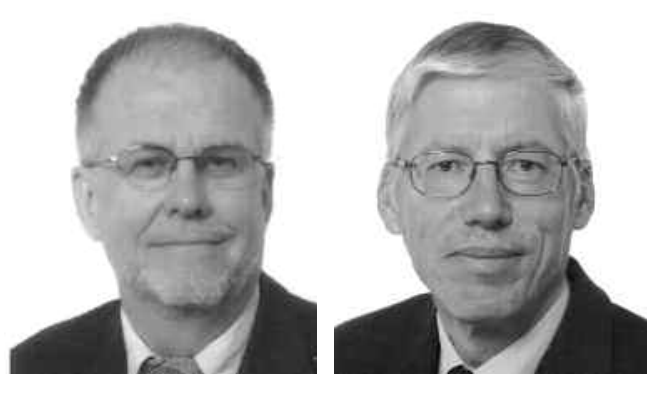

The Hydra of Greek mythology, a beast with multiple heads that grow again when cut off, has been suggested by Isenberg, et $\mathrm{l}^{1}$ to be a model of systemic lupus erythematosus (SLE). In analogy with the Hydra, SLE can present itself in a multitude of guises, usually intermittently active, with sometimes abrupt flares, sometimes prolonged periods of active disease, as well as periods of clinical remission. However, there is always a risk that the disease will reappear. Active disease may cause organ damage, and disease activity over time has been shown to be strongly associated with mortality and organ damage ${ }^{2}$. Good instruments for monitoring disease activity, organ damage, and health status are required for adequate followup of longterm outcome and judgment of response to treatment.

At every patient visit the physician should decide whether the patient's disease is active and whether disease activity is the same, better, or worse compared with the previous visit. Further, annual assessment of organ damage and quality of life should be done to enable a complete evaluation of therapeutic response and prognostic considerations.

A multitude of suggestions for disease activity assessment in SLE have been presented over the years, but few instruments have been formally validated. Among these activity indices, some are based on global score systems and some are based on individual organ system involvement.

Over the years, the Toronto SLE research group has made important contributions within this area. The original SLE Disease Activity Index (SLEDAI) was developed in Toronto in 1985 and has since been modified at several occasions. This index concentrated on new and recurrent manifestations, while ongoing activity was only partly recorded, and described global disease activity but did not provide detailed assessment of changes of disease activity in individual organs. A revision (SLEDAI-2K) was presented in $2002^{3}$ that allowed registration of ongoing activity for proteinuria, rash, alopecia, and mucosal ulcers. A great advantage is that SLEDAI-2K is easy to perform and can be registered in the routine of ordinary clinical work. Other alternative global indices are SLAM (Systemic Lupus Activity Measure) and ECLAM (European Consensus Lupus Activity Measure), which have also been validated and have shown sensitivity to change. All these global indices compare well with each other.

The BILAG (British Isles Lupus Assessment Group index) for SLE activity was developed and validated, and the latest version, BILAG-2004, was presented recently ${ }^{4}$. BILAG-2004 has the advantage of being more detailed and organ-specific than the global indices and is based on the physician's intention to treat. A possible disadvantage with this index is that careful instruction and repeated training of physicians is required to be competent to use the instrument. Further, because it is more time-consuming to perform, use of this activity index may be difficult in the daily routine where only a limited time is usually allowed for each visit. Obviously the risk of user errors is higher with BILAG-2004 than with SLEDAI-2K. One further problem might be the "intention to treat" basis, which could introduce bias when evaluating effect of treatment.

Another important issue for the physician estimating disease activity in SLE is to differentiate genuine lupus activity from damage and from intercurrent disease such as infection and malignancy. Here the need for new reliable biomarkers is obvious.

The total burden of disease manifestations, i.e., disease activity over time, is invaluable for the assessment of longterm prognosis and drug efficacy in patients with prolonged followup in "real life" or daily practice. In this issue of The Journal the Toronto group discusses in a report by Ibañez, et $a l^{5}$ the use of adjusted mean SLEDAI-2K (AMS) estimates during followup, and at what intervals patients should be seen to get a reliable area under the curve judgment of disease activity over time.

It is easily understood and obviously important to see patients at the time of flares and to do disease activity esti-

See Optimal frequency of visits for patients with SLE to measure disease activity over time, page 60

Personal non-commercial use only. The Journal of Rheumatology Copyright @ 2011 . All rights reserved. 
mates of flares within the time range of the indices, which may be difficult when the interval between visits is more than 3 months. Because some disease manifestations of lupus such as active renal involvement cause few subjective symptoms, procedures to catch such events have to be included in the followup of patients. AMS adjusts for varying time intervals between visits and is easy to calculate and interpret. However, as shown in the article by Ibañez, et al, AMS based on at least quarterly visits is more reliable than AMS based on more sparse visits, as expected.

In trials of new drugs the present disease activity indices may be not sensitive enough for detection of clinically valuable efficacy in patients with SLE. This is especially true outside of lupus nephritis. The need for improved treatment in SLE is demonstrated by the accrual of organ damage due to active disease seen in SLE cohorts followed prospectively at large SLE centers in the Western world. The difficulty in demonstrating efficacy in trials with some new biologics, somewhat in contrast to open-label experience, may be due at least partly to lack of sensitivity of the instruments for measurement of outcome ${ }^{6}$. Perhaps more important, biologics that pinpoint one receptor pathway might not be globally effective in SLE. Therefore phenotype-focused trials based on more exact mechanism hypotheses are required, and the usefulness of existing indices for such trials remains to be proven.

Thus, there is obviously a need for development and validation of accurate and reliable responder indices in this new context, which can detect and verify efficacy of new drugs in the treatment of lupus. The existing activity indices have, however, been found to work well in a few studies of the old more global therapies, such as mycophenolate mofetil and intravenous cyclophosphamide ${ }^{7}$. In this context, the findings by Ibanez, et al add useful information regarding longterm followup intervals for the calculation of AMS.

GUNNAR STURFELT, $\mathrm{MD}, \mathrm{PhD}$; OLA NIVED, MD, PhD,

Department of Rheumatology, Skane University Hospital, SE-221 85 Lund, Sweden

Address reprint request to Dr. Sturfelt; E-mail: Gunnar.Sturfelt@med.lu.se

\section{REFERENCES}

1. Isenberg DA, Horsfall A. Systemic lupus erythematosus: adult onset. In: Maddison PJ, Isenberg DA, Woo P, Glass DN, editors. Oxford textbook of rheumatology. Oxford: Oxford University Press; 1993:733-55.

2. Ibañez D, Urowitz MB, Gladman DD. Disease activity over time (adjusted mean SLEDAI) predicts mortality and damage in SLE. J Rheumatol 2005;32:824-7.

3. Gladman DD, Ibañez D, Urowitz MB. SLE Disease Activity Index 2000. J Rheumatol 2002;29:288-91.

4. Yee CS, Farewell V, Isenberg D, Prabu A, Sokoll K, Teh LS, et al. Revised British Isles Lupus Assessment Group 2004 Index. A reliable tool for assessment of systemic lupus erythematosus activity. Arthritis Rheum 2006;54:3300-5.

5. Ibañez D, Gladman DD, Touma Z, Nikpour M, Urowitz MB. Optimal frequency of visits for patients with SLE to measure disease activity over time. J Rheumatol 2011;38:60-3.

6. Bruce IN. Re-evaluation of biologic therapies in systemic lupus erythematosus. Curr Opin Rheumatol 2010;22:273-7.

7. Ginzler EM, Wofsy D, Isenberg D, Gordon C, Lisk L, Dooley MA. Non-renal disease activity following mycophenolate mofetil or intravenous cyclophosphamide as induction treatment of lupus nephritis. Arthritis Rheum 2010;62:211-21.

J Rheumatol 2011;38:3-4; doi:10.3899/jrheum.101024 